Clinical Medicine

Poster

Abstract ID: 145

\title{
Integrating islamic input in undergraduate psychiatry teaching: IIUM experience
}

Najwa Hanim Md Rosli | Md Faiz Md Tahir | Nora Mat Zin | Hanisah Mohd. Noor | Kartini Abdullah

Kulliyyah of Medine, International Islamic University Malaysia

Introduction: Since the recognition of psychiatry as a medical specialty back in the 19th century, many theories, therapies and treatment were much influenced by Western findings and practice. In general, spirituality and religion had little input or mentioning. Recently in 2012, the Royal College of Psychiatrists (London) affirmed the value of considering spirituality and religion as a part of good clinical practice which would benefit both the patient and the psychiatrist throughout the treatment period. In the Malaysian context, the general postgraduate training of psychiatrists in Malaysia does not specifically integrate religious or spiritual values in the curriculum. Methods: At IIUM, the undergraduate students are exposed to basic and essential psychology during the first year. During their fourth year they are introduced to subject of psychiatry for a short two weeks. Later in their final year, they exposed to an extensive and comprehensive 7 weeks posting covering all major topics and disorders in psychiatry. Results: In this paper, we would like to share our experience throughout the 15 years, this program has been running and discuss the challenges, limitations and future expectation in order to realize the objective of integrating Islamic input into the psychiatry curriculum in IIUM hence producing doctors who are may then treat and heal patients holistically; physically, psychologically and spiritually. Conclusions: Studies on the outcome of the integrated Islamic input in the psychiatry curriculum among the clinical students and graduates are to be carried out further in the future.

KEYWORDS: psychiatry, islamic input in medical practice, medical education 